\title{
Feasibility study and strategy analysis of low-carbon operation of large-scale sports events under the green development model: an example of building a "racing city" in Wuhan
}

\author{
Yi Ke ${ }^{1, *}$ \\ ${ }^{1}$ School of Physical Education and Equestrian, Wuhan Business University, Wuhan, China
}

\begin{abstract}
China emphasizes the need to establish a new development concept of innovation, coordination, green, openness and sharing, and to promote green and low-carbon transformation. Hubei Province is also accelerating the promotion of green and low-carbon development and continuously improving its sustainable development capacity. Wuhan, as the capital of Hubei province, is the city of car-making and the future city of racing. This paper mainly uses the literature method and fieldwork method to conduct the study and the author believes that under the green development model, through the low-carbon event operation means, the large-scale auto event will become a unique auto event brand IP, which will help expand the influence of the city, promote the low-carbon development of auto industry and sports industry, and lead the public to actively embrace the low-carbon and green lifestyle.
\end{abstract}

\section{Introduction}

In the general debate of the 75th session of the UN General Assembly, President Xi Jinping clearly proposed that "China will increase its national contribution, adopt more vigorous policies and measures, strive to peak $\mathrm{CO} 2$ emissions by 2030, and strive to achieve carbon neutrality by 2060 , emphasizing that all countries should promote green and low-carbon transformation to build a community of human destiny. One of the key tasks identified in the 14th Five-Year Plan for National Economic and Social Development of Hubei Province and the outline of Vision 2035 is to accelerate the promotion of green and low-carbon development and improve the capacity for sustainable development. Wuhan City firmly takes the road of urban transformation with ecological priority and green development, and has formulated the Wuhan City Carbon Emission Peaking Action Plan (2017-2022), with emphasis on implementing low-carbon development demonstration projects, promoting the development of green low-carbon industrial ecological chain and forming replicable model projects. Wuhan is a veritable city of car manufacturing, and is one of the six major automobile production bases in China. Wuhan Economic and Technological Development Zone (WHDZ) gathers 7 major passenger car OEMs, 12 auto assembly plants, and more than 500 auto parts enterprises, and it has high auto manufacturing and R\&D capabilities [1].
Table 1. Basic information of major passenger car enterprises in Wuhan

\begin{tabular}{|c|c|c|}
\hline No. & Passenger car OEMs & $\begin{array}{l}\text { Production and sales } \\
\text { volume in } 2020\end{array}$ \\
\hline 1 & Dongfeng Honda & 850307 units \\
\hline 2 & SAIC-GM Wuhan & 482178 units \\
\hline 3 & $\begin{array}{l}\text { Dongfeng Peugeot } \\
\text { Citroen Automobile }\end{array}$ & 50,267 units \\
\hline 4 & Dongfeng Renault & 2,688 units in first quarter \\
\hline 5 & $\begin{array}{c}\text { Dongfeng Passenger } \\
\text { Vehicle }\end{array}$ & 70180 units \\
\hline 6 & $\begin{array}{l}\text { Geely Automobile } \\
\text { Wuhan }\end{array}$ & $\begin{array}{c}150,000 \text { units annual } \\
\text { production capacity plant } \\
\text { under construction }\end{array}$ \\
\hline 7 & Dongfeng Nissan & 1119008 units \\
\hline
\end{tabular}

In the context of Sustainable development, Wuhan is paying more attention to the low-carbon green transformation and development of the automotive industry, and has made a series of major new energy vehicle industry layout, Wuhan proposed to introduce 2 to 3 new energy vehicle OEMs by 2025, and in April 2021, has successfully introduced the famous new energy vehicle company Xiaopeng Motors. The vehicle and powertrain factory built by Xiaopeng Motors in Wuhan covers an area of about 1,100 acres, with a planned annual production capacity of 100,000 vehicles. Wuhan has taken strong measures to promote the development of the new energy vehicle industry, which has not only boosted the overall automotive industry chain in Wuhan and the synergistic development of the 
surrounding supporting industries, but also has a positive significance and leading role in the economic growth of the region, especially the green and low-carbon economic development. At present, Wuhan is actively building a racing city, with Green development model, low-carbon operation of automotive events can vigorously develop the automotive service industry, strengthen and improve the automotive industry chain in Wuhan, boost the healthy development of the local automotive industry, pull the development of new energy vehicles, and also make a good demonstration for green low-carbon development.

\section{Necessity}

\subsection{Create an auto racing series IP to expand the influence of the city.}

Compared with foreign countries, the history of Chinese motor sports is relatively short. After entering the $21 \mathrm{st}$ century, Wuhan has been trying to accumulate experience in motorsports. 2002 was the first time that an international car rally, the Asian Rally, landed in Wuhan, and in 2015, 2016 and 2017, Wuhan held three consecutive China Drift Championship (CDC), and in 2017, CTCC China Touring Car Championship. In 2018, the first China Automobile and Motorcycle Sports Festival was held in Wuhan, attracting about 100,000 spectators to the first conference [2].

Wuhan is making every effort to permanently locate the China Automobile and Motorcycle Sports Festival in Wuhan, and racing will become a major city brand and event IP of Wuhan. Wuhan will also build a highstandard, professional racing circuit with International Grade II tracks, and plans to introduce a number of international and domestic top motorcycle events after completion of the circuit. Branded sports events can also become an engine for economic development and create new economic growth points. By continuously improving and upgrading the supporting infrastructure and overall service functions of the event, Wuhan's auto racing influence will gradually expand, attracting more events to land and truly forming a new storm center for motorsports, thus expanding the city's influence and promoting economic transformation and development.

\section{2 promote the development of Wuhan's automobile industry and the industry chain.}

By holding a series of events to attract more social capital and forces to join the motor sports industry, Wuhan racing brand will be enlarged and strengthened, further promoting the development of the sports event industry and making the supply of sports products and services in the region more abundant and complete. Wuhan is the city of cars and most of the city's automobile OEMs are located in WHDZ. Motorsport matches the characteristics of the automotive industry in Wuhan Development Zone, and the vigorous development of motorsport can not only create new economic growth points for the city, but also promote the continuous transformation of the regional automotive industry.

In auto races, each participating team has a large service support team containing a large number of technical, maintenance and service members, plus a large number of media and spectators. The human traffic brought by auto races can greatly promote the development of the local tertiary industry, especially bringing great business opportunities to the accommodation, catering and tourism industries, and will also bring great impetus to the economic and social development of the city. The continuous development of auto races will attract more auto manufacturers to participate in auto races directly or indirectly. Through the events, auto manufacturers can test and demonstrate newly developed auto technologies, continuously improve the overall quality of vehicles and promote the technical progress of the auto industry, as well as carry out brand marketing more effectively, enhance brand awareness and promote their own auto culture concepts. The growth of auto events will also further expand the development scale of auto derivative markets such as racing training and auto tuning, and promote the healthy development of the entire auto industry chain.

\subsection{Boost the high-quality development of national sports industry demonstration base with Green collaborative innovation.}

WHDZ is rich in sports resources, with high-standard sports venues such as Wuhan Sports Center. It has hosted international large-scale events such as the World Military Games in recent years, with obvious sports industry gathering effect, considerable industrial foundation and scale, which has played an extremely strong leading and demonstration role in the development of sports industry in the region and the surrounding areas. In 2019, WHDZ was approved by the State General Administration of Sports as a national sports industry demonstration base. At present, Wuhan is vigorously building the 'City of Racing', and it is necessary to give full play to the city spirit of "Dare to be the first, pursue excellence", and vigorously innovate the organization, competition and activity forms of automobile events. By means of low-carbon operation and integration of new energy elements, Wuhan will create a unique and appealing series of auto racing brands and form a rapid gathering effect of the racing industry to boost the construction of a national sports industry demonstration base.

\section{Feasibility}

\subsection{Policy support for large-scale sports events}

The Outline for Building a Leading Sports Nation issued by the State Council points out that it is necessary to accelerate the development of the sports industry, cultivate new dynamic energy for economic development, and create a number of well-known sports enterprises with international competitiveness and 
independent sports brands with international influence. The People's Government of Hubei Province issued the Opinions on Accelerating the Transformation of Development and Promoting the Construction of a Strong Sports Province, which clearly states that we should activate industrial elements, promote the sports industry as a new economic growth pole, and cultivate and create high-level events. 2021 Hubei Provincial Sports Work Conference pointed out that by 2025, the main indicators of sports development in Hubei should be higher than the national average, and basically build a strong sports province.

Wuhan, as the capital of Hubei Province, has taken up the role in the strategy of building a strong sports province in Hubei Province, and has held and hosted many domestic and international large-scale sports events for many years, gradually expanding its sports influence. The National Sports Industry Demonstration Base is the national support and recognition for the development of Wuhan's sports industry. Therefore, Wuhan has strong policy support from the national, provincial and municipal levels to create special sports events and innovate event management and operation.

\subsection{Automotive industry scale and scientific and educational strength support}

As mentioned earlier, the automotive industry has been the main pillar industry of Wuhan. The city has a complete and mature automotive industry chain, and motorsport has high-quality industrial support and convenient resource channels. Wuhan has strong strength in science and education, and many famous universities have auto-related majors and strong R\&D capabilities in the auto industry. In particular, China's first racing college, China Racing College was officially established in Wuhan's Jianghan University in 2018, and this academy can train a large number of technical and management talents in the racing industry every year, which will be the talent resources and core guarantee for the healthy development of local motorsports industrialization.

\subsection{Ability and experience in operating sports events and good sports mass foundation}

First, Wuhan is a strong sports city with a gathering of large-scale events, and in recent years it has held the 7th World Military Games, Wuhan Open Tennis Tournament, Asian Badminton Championships and other large-scale international events. In particular, Wuhan has been hosting international-level auto events since 2002, accumulating a lot of experience in auto events and professional technical strength.

Secondly, according to the relevant data of Wuhan Sports Bureau 2021, Wuhan has a large base of sports participation population and sports events have a huge mass base and development potential [3].
Table 2. Basic data of mass sports in Wuhan

\begin{tabular}{|c|c|c|}
\hline No. & Items & $\begin{array}{l}\text { Data as of } \\
\text { January } 2021\end{array}$ \\
\hline 1 & $\begin{array}{c}\text { Sports population regularly } \\
\text { participating in sports in } \\
\text { Wuhan }\end{array}$ & $3,948,800$ \\
\hline 2 & $\begin{array}{l}\text { The number of city-wide } \\
\text { sports venues }\end{array}$ & 29538 \\
\hline 3 & Total area of sports grounds & $\begin{array}{l}23.5891 \text { million } \\
\text { square meters }\end{array}$ \\
\hline 4 & $\begin{array}{l}\text { City and district sports } \\
\text { associations }\end{array}$ & 292 \\
\hline 5 & $\begin{array}{l}\text { pass rate of citizens' physical } \\
\text { fitness sample }\end{array}$ & $91.8 \%$ \\
\hline 6 & $\begin{array}{l}\text { Streets and towns that have } \\
\text { built cultural and sports } \\
\text { service centers or } \\
\text { comprehensive service centers }\end{array}$ & More than $90 \%$ \\
\hline 7 & $\begin{array}{c}\text { Annual national fitness } \\
\text { activities }\end{array}$ & $\begin{array}{l}\text { More than } \\
1,000 \text { times }\end{array}$ \\
\hline
\end{tabular}

\section{Strategies}

\subsection{Auto racing should highlight the "green" label}

Unlike other sports, motor sports are closely related to industry and have a history of more than 100 years since their origin. The world's three most famous car races: Formula 1, 24 Hours of Le Mans and WRC are very popular and influential all over the world. Under such background conditions, Wuhan, as a latecomer to motor sports, cannot stick to the routine, otherwise there may be no way out and no future. At present, we must highlight the low-carbon and green elements, create a different brand of auto racing, leading with Low carbon economy development, and win more recognition and welcome, so that we can possibly overtake in the field of motor sports, otherwise it is difficult to compete with other international large auto races.

\subsection{Auto racing should vigorously integrate new energy elements}

With energy and environmental problems becoming more and more prominent, the development of new energy vehicles represents the development direction of the world automobile industry [4]. The country has laid out four national industrial bases in Wuhan, including the New Energy and Intelligent Networked Vehicle Base in WHDZ. Under the favorable policy and the trend of the times, Wuhan has vigorously promoted the construction of this base, and in recent years, many new energy vehicle research institutions and OEMs have taken root here, helping to transform and upgrade the traditional automobile industry to next-generation vehicles. Therefore, there is a good industrial base and resource conditions for developing new energy vehicle races in Wuhan. 
The integration of new energy elements can be achieved by adding new energy car competition items to traditional car racing events, or by creating brand new new energy car racing events and refining the competition sub-items: such as acceleration duel, safety challenge, energy saving competition, etc. Encourage more new energy car enterprises to participate in it, and jointly expand the scale and influence of new energy car events, which is not only beneficial to the publicity of new energy car enterprises, but also conducive to increasing the mutual exchange and display between car enterprises, promoting the overall improvement of technical strength, and also attracting more people to know and understand new energy cars, promoting the popular promotion and application of new energy cars, and truly boosting the development of low-carbon economy.

\subsection{Low-carbon operation should run through the whole process and all aspects of the car race}

Race organizers should reduce operational costs, improve race efficiency and reduce resource waste through low-carbon O\&M, and create innovative lowcarbon events with universal participation and good interaction by developing and using low-carbon products and services.

Green and low-carbon elements should be incorporated into the whole process and all aspects of the operation of auto racing. First, low-carbon elements should be incorporated into the planning and marketing of the event from the early stage. Using low-pollution and easy-to-recycle materials for event advertising, packaging, and peripheral products to reduce physical or paper-based publicity and expand online publicity channels. Secondly, we should develop and apply intelligent event systems in event management to optimize the management and control of the large amount of logistics, human and vehicle flows involved in auto events with low-carbon concepts. Thirdly, we should strongly introduce green, low-carbon and energysaving auto competition panels in the event program to attract people's attention to the direction of energy conservation and emission reduction advocated by the auto industry. Fourth, we should innovate and design interactive services for the event spectators. For example, a low-carbon personal action challenge competition can be organized, with rewards such as discounted ticket purchase and gift exchange based on participation results. Or by developing event apps or mini programs, organizers can give low-carbon score rewards to spectators for taking public transportation, riding, bringing their own utensils and water cups, etc. Through these innovative designs, guide the public to develop a green lifestyle and create a low-carbon event atmosphere of universal participation in energy saving and emission reduction.

\subsection{Scientific and reasonable traffic control for auto racing}

For auto races, traffic control is even more important. At the 2019 China Automobile and Motorcycle Sports Festival, the organizers in Wuhan have made temporary adjustments to 19 bus routes to match the smooth running of the competition activities and ease the congestion on the roads around the competition. As Wuhan further builds a city of racing, more auto events are bound to be introduced, and the frequency of implementing traffic control may increase with the events. In this case, we have to take multiple measures to reduce the scope and impact of traffic control and avoid causing greater disturbance to local residents and commuters by reasonably selecting the race venue, optimizing the layout of the race venue, optimizing the access flow to and from the race venue, and encouraging the public to choose public transportation during the race. Reasonable traffic control not only can promote the smooth running of the event, but also is a concrete practice to improve the efficiency of the event, energy saving and emission reduction, which can better promote the economic development of the hosting city [5].

\section{Conclusion}

Wuhan is the city of automobile and is also building the city of racing, and the introduction of a series of auto races in the future has been an inevitable trend. In the context of low-carbon economic development pursued by all countries in the world today, the automobile industry is also seeking green transformation development and encouraging low-carbon innovation. Wuhan should seize the policy opportunity and lead the trend of the times by virtue of the dual advantages of national automobile industry base and sports industry demonstration base, and build large-scale racing events with low carbon methods, and through unique operation of car racing events, Wuhan will further expand the influence of the city, promote the low-carbon development of the automobile industry and sports industry, and lead the public to actively embrace a lowcarbon and green lifestyle.

\section{References}

1. Sun Yansong. "Deep thoughts on the post-epidemic development of Wuhan automobile industry." Automotive Observation.10 (2020):66-70.

2. https://kuaibao.qq.com/s/20191205A0Q83P00

3. http://tyj.hefei.gov.cn/xxsd/lmdt/14698143.html

4. Lei Ming. "Exploration of economic development of new energy vehicle races in Tianjin." China Urban Economy.05 (2010):128+113.

5. Li Jia. "Analysis of the economic effect of large sports events and its optimization strategy---The 13th National Games as an example." Journal of Shenyang Institute of Sports 38.03 (2019):83-88. 